\title{
Contradictory agendas in health visitor needs assessment. A discussion paper of its use for prioritizing, targeting and promoting health
}

Sarah Cowley King's College London, London UK; and Anna Houston Research and Development Department, The Link Centre, St. George's Hospital, Hornchurch, UK

This paper was motivated by the adverse results of a study that evaluated implementation of a structured health needs assessment tool in health visiting. It examines the conceptual basis of three approaches to needs assessment, exploring their relevance to the purpose of health visiting and their links with prioritizing, targeting and promoting health in practice. It is intended to help health visitors, their managers and service commissioners to explain and understand the different requirements and expectations in each approach.

British Government policy emphasizes that targeting and prioritizing are the means by which inequalities can be redressed and resources directed towards those in greatest need. Needs assessment processes are increasingly invoked as the mechanism through which health visiting services can best be deployed. Health visitors are expected to help identify service priorities and to target their efforts effectively and efficiently. Access to services and user empowerment are also important aspects of the NHS modernization agenda. These concepts are fundamental to health promotion, which has been the consistent underlying purpose of the health visiting service since its inception.

In this discussion paper, three approaches to needs assessment are unravelled, which focus on prioritizing, targeting and health promotion. It is suggested that these different purposes relate, in turn, to the expectations and requirements of public health, organizational efficiency and user empowerment. There are important benefits associated with each of the three approaches, but their underlying principles, purposes and requirements differ. Failure to appreciate such differences can lead to misunderstandings, confusion and even offence. A single instrument cannot successfully meet the expectations of all three approaches to needs assessment. Instead, a needs assessment system is necessary, to meet the contradictory requirements of public health, organizational efficiency and user empowerment.

Key words: empowerment; health visiting; health promotion; prioritizing; public health; targeting

\section{Introduction}

In the UK, an increased emphasis on both family welfare and public health accompanied a change of government in 1997 (e.g. Department for

Address for correspondence: Sarah Cowley, King's College London, Fifth Floor, Franklin Wilkins Building, 150 Stamford Street, London SE1 9NN, UK. Email: sarah. cowley@kcl.ac.uk
Education and Employment (DfEE), 1999; Department of Health (DH), 1999a; 2001a; 2002a; Her Majesty's (HM) Treasury, DH 2002; Home Office, 1998). These two issues are connected by new acceptance of the links between poor health and socioeconomic disadvantage, especially the long term health impact created by disadvantage in childhood (DH, 2003; Feinstein, 1998; Graham, 1999; Independent Inquiry into Inequalities in Health, 1998). Health visitors are expected to 
contribute to both these areas of change by developing 'a family-centred public health role, working with individuals, families and communities to improve health and tackle health inequalities' (DH, 1999b: 61). Health visitors have always been public health workers, but there is some debate about whether the change in emphasis is a continuation of familiar practice, or a completely new role (Craig and Smith, 1998).

The majority of health visitors are based within primary care, generally deriving their case-load from the general practice list. They offer health promotion and support to all families with preschool children and, increasingly, across a wider age range, for purposes of public health. The service has some similarities with the widespread home visiting programmes in North America (Gomby et al., 1999) and with the provision offered by various primary care or public health nurses in other countries. However, the organization, focus, client group responsibility and individuals' entitlement to these services varies markedly from one country to another (Hanafin et al., 2002). This inevitably limits the transferability of research across settings. This contextual variation has an effect upon the way decisions are made about which clients receive the service as well, with changes in macrosocial policies being a strong influence in the long term (Dingwall, 1977; Robinson, 2000).

Despite the context-bound nature of this form of service provision, it seems likely that there are ideas and concepts in common across services. However, understanding of concepts may differ, even where the same terminology is used. The phrase 'needs assessment' is widely used, for example, although its connotations and application vary quite markedly across disciplines (Billings and Cowley, 1995; Lightfoot, 1995). Shared understanding is important in the context of multidisciplinary working in primary care, which offers the potential benefit of learning across different professional groups. Conversely, problems may arise if approaches from one professional group are implemented into the working practices of another, without fully understanding the implications of potentially different underlying beliefs and concepts in practice. The purpose of this paper is to aid understanding and explanation of needs assessment practice within health visiting and related services.

\section{Health visitor needs assessment}

The motivation for writing this paper came from the results, reported elsewhere, of a study about the use of a locally developed, structured needs assessment tool in health visiting (Cowley and Houston, 2003). Service managers had been challenged by public health specialists within the commissioning organization, to demonstrate that their health visiting services were purposeful and reaching those who were most in need. The organization was financially hard-pressed and the managers were keen that their service should operate in the most efficient way, so they introduced a structured health needs assessment tool through which health visitors might determine the frequency of future contacts with clients. The instrument was developed, with research advice, by a working group of managers and health visitors. It was introduced with an accompanying training programme that stressed the importance of proactive health promotion and of health visitors working in partnership with their clients. However, there was much controversy about the instrument locally, with practitioners being divided about the merits or otherwise of the approach.

The resulting in-depth qualitative evaluation revealed a number of difficulties (Cowley and Houston, 2003; Houston and Cowley, 2002). The instrument was neither valid nor reliable as an epidemiological instrument, nor effective for eliciting health needs, particularly for the most vulnerable clients. A number of clients revealed that being asked the questions increased their stress and anxiety and, for some, it inhibited their use of health services. Even those health visitors who, broadly speaking, approved of the instrument, found some difficulties with its use in practice, whilst others found it deeply offensive and intrusive. In the light of these results, an extension to the original study was carried out, to explore whether the difficulties identified in one place might exist elsewhere. In the second organization, a different structured instrument was in use. This had been developed elsewhere (Crompton et al., 1998, Naughton and Heath 2001), but adopted at the research site with little apparent controversy. Conversation analysis methods were used to examine how the two different, structured instruments 
were implemented in practice in their respective research sites. Whilst there were differences in the way they were used, in both sites, the instruments appeared to focus attention on to the organization's agenda instead of the clients'. The primary focus, when the instruments were used, appeared to be on asking questions instead of listening to answers, minimizing the importance of interpersonal relationships, communication and opportunities for client participation or empowerment (Mitcheson and Cowley, 2003).

Similar, locally developed instruments or guidelines have been introduced by many organizations. Although no recent figures are available to indicate frequency, a national survey carried out in England in 1996 indicated that such instruments formed the basis of the contracts through which health visiting services were funded in around one-third of organizations, with a further third expecting them to do so in the near future (Appleton, 1997). An in-depth, follow-up to this survey revealed that health visitors largely ignored the 'official' guidelines and instruments in practice, instead, using a sophisticated process of professional judgement to determine whether to offer additional contacts to clients (Appleton and Cowley, 2003).

Given the problems in use and potential for harm from the distress caused, it has been argued elsewhere that similar structured assessment tools should not be used in routine clinical practice to determine the intensity of health visiting contacts (Cowley and Houston, 2003; Mitcheson and Cowley 2003). However, the challenges faced within the organization where our research began remain real. British Government policy emphasizes targeting and prioritizing as mechanisms through which inequalities can be redressed and resources directed towards those in greatest need (Department of Health (DH) 1999a; 2001a; 2002a; 2003; Her Majesty's (HM) Treasury and DH 2002). Needs assessment processes are increasingly invoked as the mechanism through which health visiting services can best be deployed, with health visitors being expected to help identify service priorities and to target their efforts effectively and efficiently (DH 1999b; 2001b; 2002b). Access to services and user empowerment are also important aspects of the government's drive to 'modernize' the National
Health Service (NHS) (DH 2000; 2002b). These concepts are fundamental to the promotion of health and social well-being, which has been the consistent underlying purpose of the health visiting service since its inception (Council for the Education and Training of Health Visitors (CETHV) 1977; Nursing and Midwifery Council (NMC) 2002a).

It is suggested in this paper that the challenges stemming from the need to prioritize, target and promote health relate, in turn, to the expectations and requirements of public health, organizational efficiency and user empowerment. Each of these requirements is legitimate and important and each may, in different ways, be associated with, and well served by, the use of particular approaches to needs assessment. However, the underlying principles, purposes and requirements of the approaches differ, which can lead to misunderstandings, confusion and occasional ethical problems if they are applied inappropriately. There appear to be some inherent contradictions between them which, if not fully understood, are likely to lead to the kinds of problems and constraints indicated by the research cited above.

Three approaches to needs assessment which focus upon prioritizing, targeting or on health promotion will be unravelled in respect of their use within health visiting services. It will be argued that a single instrument cannot successfully meet the expectations of all three types of needs assessment at once, because their purposes, being drawn respectively from a base in public health, organizational efficiency and user empowerment, lead to different requirements that are not all compatible.

\section{Prioritizing health visiting services}

Dictionary definitions reveal that the term 'priority' signifies a form of precedence; it is associated with having the right to be first, or a superior claim to attention (Hawkins, 1990). In public health, decisions about which population groups or areas should be regarded as a priority are informed by an epidemiological assessment of needs in an area, but the political process is also very influential. Inequalities in health and their association with socioeconomic factors were well documented throughout the 1980s and 1990s, for 
example, but they were not a priority for the former government (see, for example, Benzeval et al., 1995; Wilkinson, 1996).

Also, there is a distinct difference in emphasis between the current political view that young families all need and deserve some support (Chief Secretary to the Treasury, 2003; Home Office, 1998), and the former opinion that families could be left to seek help if they thought they needed it (NHS Executive, 1996). The kind of universal contact offered by health visitors to all families with children under school age may be construed as 'interference' in this second view. Consumer studies demonstrate that service users experience health visiting as 'supportive' in some circumstances and 'interfering' in others (Machen 1996; Normandale 2001; Pearson 1991). The way a service is set up and individual staff attitudes both appear important in determining which experience predominates.

As public health workers, health visitors are trained and expected to profile the health needs arising in the case-load they hold, and to set priority areas for attention by analyzing those needs in conjunction with local epidemiological data (DH, 2001b). The extent to which this actually happens in practice is disputed. Young and Haynes (1993) found little evidence of case-load profiling in their study. Likewise, Cowley et al. (2000) found it was uncommon; the few practitioners who had compiled health needs profiles had done so in their own time. In the rest of their sample, from 23 different trusts across England, some had no wish to undertake this activity; others were actively discouraged by either their managers or their work-load.

The lack of value afforded to profiles compiled by practitioners may link to their relatively junior position in the overall organization of the NHS (Cowley et al., 2000); prioritizing by health visitors within their case-load may be not allowed or not acknowledged where it does exist. Setting priorities tends, instead, to be considered a senior managerial or commissioning function, with decisions informed by population units large enough to be statistically significant, robust and reliable in epidemiological terms; a single case-load is too small for this to apply.

When applied to health visiting services, the public health, prioritizing approach to needs assessment legitimately seeks to identify geographical areas or population groups that would most benefit from attention from this profession. Health visitors working in deprived areas are likely to have higher (sometimes far higher) numbers of families with specifically identified problems than in non deprived areas (Shephard, 1996); their need for social and emotional support is particularly high (Rowe et al., 1995; Shephard 1992). Also, the constraints created by poverty lead to greater difficulties for the families concerned and call for considerable skill and sensitivity on the part of their health visitors. Awareness of this has been used to reduce the number of health visitors, thus increasing their case-load size, in areas with low deprivation scores (Cowley and Houston, 1999).

However, if a redistribution of resources is deemed necessary, it would be better based on a demonstrably robust, valid and reliable assessment of needs. Horrocks et al. (1998) have identified a system of weightings based upon factors derived from health visiting case-loads. This approach has the potential to develop staffing ratios that are more sensitive to identified needs than those derived from straightforward electoral ward or area-based deprivation scores, particularly where the health visiting case-load is not geographically derived and, therefore, not coterminous with the score. However, in systems like that identified by Horrocks et al., objectivity and consistency are paramount, so the wording of an instrument, once validated, should not be altered and training in its use is important. The level of abstraction needed to achieve validity results in a list of factors that are fixed, using rather judgemental terminology which is likely to render them unsuitable or unacceptable for everyday use with clients.

Horrocks et al. (1998), for example, list the 28 factors that are most significantly associated with an increased need for health visiting, including factors like "physical (or verbal) violence in the family' or 'one/both parents [are] significantly depressed' or 'abuse drugs'. Such items clearly increase the need for health visiting time, but that is not the same as suggesting that a health visitor should use that terminology when assessing the needs of an individual family. Horrocks' team was clear that their research was concerned with evaluating a case-load weighting scheme and not with assessing individual clients. Indeed, 
they point to the tendency of such prioritizing exercises to emphasize child protection factors, which is only one among many important aspects of health visiting.

However, in Cowley and Houston's (2003) study, similar questions to those devised by Horrocks et al. were present in the assessment tool. Assessing individual needs with a questionbased approach led some clients to feel judged and distressed. Others expressed concern and anger, when they discovered that information, given (they believed) in confidence to health visitors planning the service they would receive as individuals, was then being passed to managers for organizational purposes. In the second study area, child protection was a major focus for the structured instrument (Naughton and Heath, 2001), but it was generally used covertly by the health visitors, so clients were unaware of what information was held about them, or how it was used (Mitcheson and Cowley, 2003).

It is an accepted part of epidemiological practice to aggregate anonymized data about, in particular, notifiable diseases and official diagnoses provided on, for example, admission to hospital; such data are fundamental for public health planning. However, some wider debate seems to be indicated about the extent to which it is ethically acceptable to extend this approach to include the aggregation of attributable social information about such sensitive issues as housing tenure, civil status (e.g. about asylum seekers), substance misuse or violence in the home. Such personal information may be very significant for the type and extent of personal support required by a family, but information collected for clinical purposes cannot be made freely available for purposes of workload management or public health assessments without the informed consent of the person from whom it was collected. Without consent, a health visitor obtaining such information about a client, then submitting it for organizational purposes, is open to accusations of breaching the confidentiality they are enjoined to maintain under their professional code of conduct (NMC, 2002b). If asked, clients may be very happy to consent to their personal information being used for organizational purposes, as long as the information is fully anonymized.

Also, the priority afforded to alleviating current (albeit unequally distributed) health problems, or to preventing future inequalities is a significantly political decision. Health inequalities are mainly social in origin with many factors stemming from infancy, early childhood and family life (Feinstein, 1998; Wadsworth, 1996; 1999; Fonagy, 1996). In 1997, the incoming government commissioned a wide-ranging review of studies about inequalities in health, and approaches that might improve the situation in the future. The Independent Inquiry into Inequalities in Health (1998) summarized the position thus:

While remedial risk factors affecting health
occur throughout the life course, childhood
is a critical and vulnerable stage where poor
socio-economic circumstances have lasting
effects... there are many potentially ben-
eficial interventions to reduce inequalities in
health... many of those with the best
chance of reducing future inequalities in
mental and physical health relate to parents,
particularly present and future mothers, and
children (p. 9).

The inquiry went on to strongly recommend that more attention be paid to social and emotional factors, naming health visitors as the occupational group to be charged with a lead role in delivering these interventions. It was a very clear call to prioritize, for purposes of public health, the group that have been the traditional focus of health visiting attention: families where there are pregnant women and those with young children. Establishing this as a priority focuses attention on the policy debate about whether such services should be offered universally to all, or targeted at particular groups, individuals or areas (Elkan et al., 2001).

\section{Targeting health visiting services}

Targeting is a different process to prioritizing; the dictionary reveals that it involves having an objective or a minimum result at which to aim (Hawkins, 1990). Targeting the service, or aiming the resources more precisely, is not only a mechanism through which costs can be contained; it is also concerned with responding effectively to particular problems or causes of problems ('determinants of health') that have been identified as 
needing attention. In practice, this means an assessment that a specific need exists must take place; then a prescribed treatment or (to use terminology that is more familiar to health visitors) a 'programme of care' can be initiated.

This form of needs assessment is essentially a screening and diagnostic process undertaken to confirm whether or not a particular problem or need exists. This may be problematic for health visitors, whose primary function is to prevent problems from happening in the first place, rather than picking up established disorders and treating them. Even so, secondary and tertiary prevention are extremely valuable approaches that have the benefit of yielding ready measures of activities to be counted for organizational purposes. To be valid, a needs assessment activity carried out for the purpose of targeting should have the same attributes as any useful diagnostic test. Such a test should be sensitive, picking up people who have the condition and be specific, excluding people who do not have the condition and be accurate, revealing the correct result (not false positives or negatives) (Greenhalgh, 1997). In many instances, this will involve use of a structured instrument, validated for a particular condition.

The main reason for identifying the existence of a problem is so that it can be alleviated, so the availability of a known, effective treatment for the condition being targeted is important. One much cited example of a well validated screening test for use by health visitors is the Edinburgh Post-natal Depression Scale (Cox et al., 1987). This is a short, 10-item questionnaire that can be given to new mothers to assess their mood and, therefore, their likelihood of developing depression soon after the birth of the baby. If positive, a programme of care in the form of a short series of 'listening visits' can be offered, as this early intervention has been shown to be very effective in reducing the impact of post-natal depression (Holden et al., 1989).

Other areas of diagnostic interest for health visiting might focus, for example, upon childhood behaviour, relationship difficulties or child protection. Introducing a general screening test for any specific condition is likely to have the effect of directing the health visiting service towards that area of interest, and away from others.

In this respect, the process of targeting can be seen to overlap with that of prioritizing, so the choice of which screening activities to use could be made in the light of anticipated health needs identified at an overall, neighbourhood or locality level. One example is the use of Sure Start Language Measure (SSLM) (Harris, 2002; Sure Start Unit, 2001), which also highlights the benefits of the screening approach for evaluating organizational efficiency. Sure Start is a complex community initiative, including health visiting services, directed at families with children under 4 years old in a circumscribed geographical area, prioritized for additional funding because of measurable deprivation (Houston, 2003). The SSLM is designed to measure parental perceptions of a 2-year-old's language development as part of a national, ongoing comparative assay to assess over time whether the extra input leads to measurable gains in language for preschool children. In a number of places, having discovered the extent of difficulties, community health workers led by health visitors have targeted the problem by developing child-focused interactional opportunities for families to prevent communication delay.

A further, less desirable result of these screening activities is that they tend to focus health visiting attention on to individuals (whether mothers or children) with specified problems, instead of on the underlying social and contextual causes of the problems. In theory, health visiting has always focused upon these wider determinants of health. The extent to which that has happened in practice in the past is doubtful, but the current policy emphasis is stressing this public health aspect of the role above the importance of the work with individuals (DH, 2001b). If a need (like, for example, delayed language development) has been deemed so prevalent in an area that all families are to be screened for this condition, some parallel community-wide activities are needed to challenge and change the underlying causes of the problem.

Assessing specific needs in order to target practice effectively should be contrasted with the widespread efforts to find a way of selecting from a general, undifferentiated health visiting caseload those families who require an 'additional' service: that is, over and above the minimum contacts offered to everyone. Elkan et al. (2000) detail numerous failed attempts within health and social care since the 1960 s, to selectively screen 
those infants or families who are 'at risk' in some general way. Elkan et al., (2001) question whether it is feasible to develop a valid and reliable way of predicting, from amongst the whole population, those individuals who will develop unspecified health problems. Citing the late epidemiologist Geoffrey Rose, they emphasize the importance of retaining a universal focus for health visiting services, because 'the bulk of health and social problems occur in the large number of people who are not especially at risk, rather than in the few who are at high risk' (Elkan et al., 2001: 117).

Furthermore, identifying the 'problems' faced by families gives no indication of their strengths, resiliency or available coping resources. This may account for some of the difficulty in identifying a screening instrument that will successfully predict which families will eventually need more help than others; it also explains some of the sense of grievance and stigma expressed by those labeled as 'at high risk' (Cochrane 1986; Cowley and Houston, 2003). Also, Appleton (1997) found no instruments that were valid in her national survey, despite their widespread use in contracts and resource allocation. There are, therefore, a number of ethical questions to be asked about the use of these generalized and invalid screening guidelines.

In summary, fully validated screening tools will show sensitivity to the target condition, be specific and accurate. Such instruments are to be welcome, as they allow health visitors to target their efforts on individuals whose needs are clear and for whom effective help is available. Where a condition is prevalent, some parallel public health initiative to target the underlying cause of the problem in the wider community would be advisable. Invalid screening tools may serve as a mechanism by which some clients are enabled to access health visiting support but would potentially miss others whose needs may be equally severe or worse, or falsely identify families who are able to cope without additional help. Such instruments have no place in an evidence-based, clinically effective service.

\section{Conceptualizing needs assessment}

The two approaches to needs assessment described so far, appear conceptually related to the familiar medical ideals of, first, reaching a diagnosis, then offering some form of prescribed response, whether at a population-wide (public health) or individual (screening) level. This systematic, epigenetic approach, in which each step must be completed before the next begins is shown in Figures 1 and 2. Although assessments are periodically reviewed or revisited, leading to a cyclical process, both models are broadly unidirectional, with needs assessments being seen as essential, but separate from and preliminary to the 'main business' of delivering health care. This may be a programme of care for an individual with an identified need, or an area-based project grant if a high level of need is measured locally. If the assessment reveals that there are "no problems' then it is assumed there is no need for the individual to receive a service and a caseload or area so assessed may be weighted to allow for only a minimal level of health visiting contact or no additional project grants. Again, the need for further research and debate about the relative effectiveness of geographically targeted or universally delivered services is well acknowledged (Roberts, 2000) but, conceptually, a step-by-step process that leads to the provision of a service or not, remains clear.

\section{Promoting health through needs assessment}

In contrast, the third approach to needs assessment is integrally bound up with the delivery of health visiting and serves a health promoting purpose whether or not there are 'identified problems'. Central to the effectiveness of health promotion is the need to ensure that practice allows and enables empowerment of clients, at both an individual and a structural level (Kendall, 1998). In this approach, therefore, the assessment process is regarded as an opportunity to promote and develop what Kieffer (1984) has dubbed 'participatory competence' on the part of the client, whose position he describes in terms of citizenship and empowerment.

This approach appears to be widely used, or at least intended, by health visitors in practice. It is little described in the literature as a specific "needs assessment approach' although further details are set out in Houston and Cowley (2002). Of the three approaches, it is possibly the most firmly 

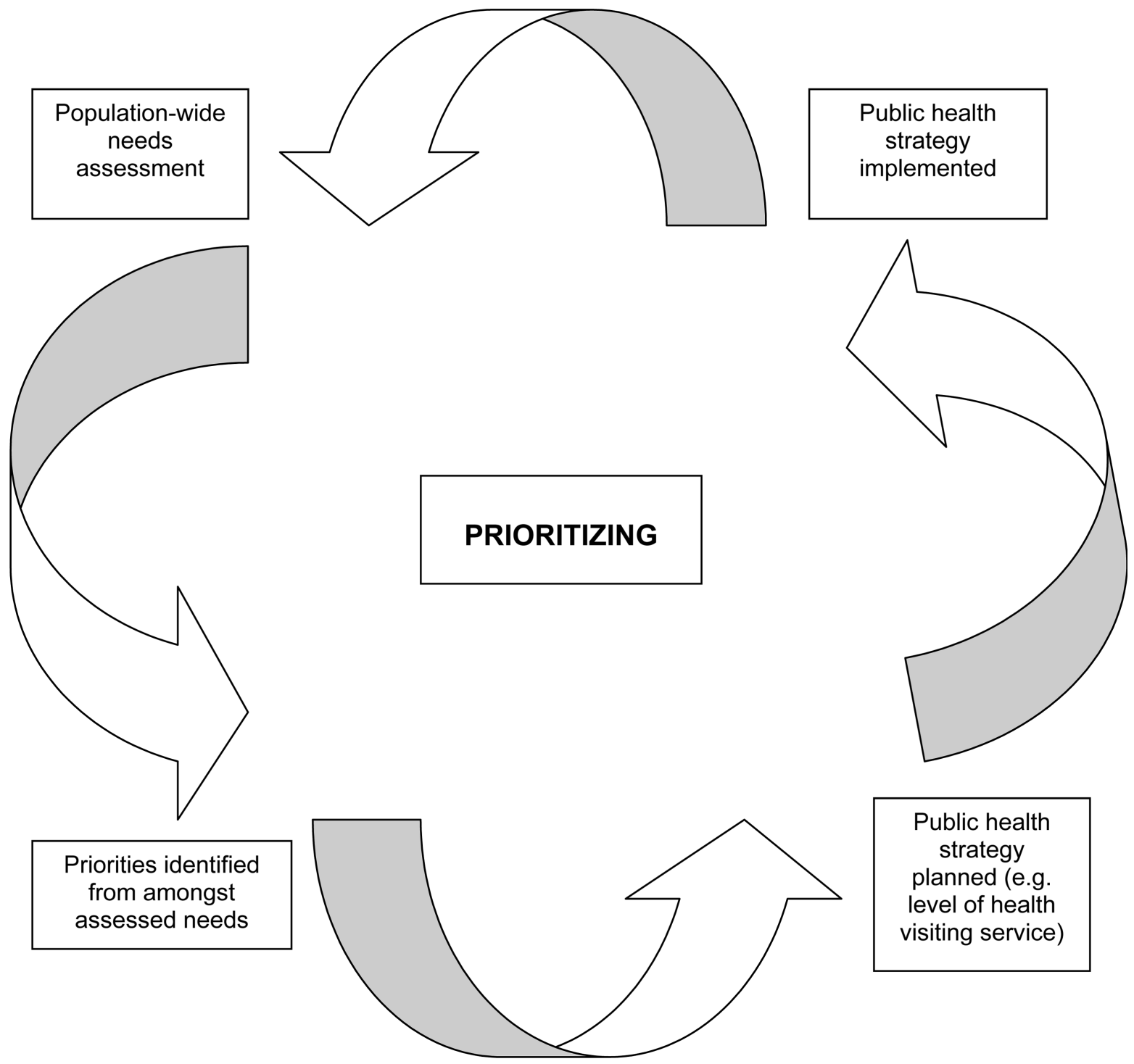

Figure 1 Needs assessment for purposes of prioritizing

based upon the principles and philosophy of health visiting (CETHV 1977; NMC 2002a). The ideas are grounded in a wealth of health visiting and health promotion research, summarized in Table 1, although there is no direct evidence about the extent to which they are successfully implemented, nor of the health impact of this approach. The health promotion remit in the empowerment approach is, in theory at least, extended into the wider situation (that is, in the local community or sociocultural context) in which the families live, in order to meet the public health imperative to focus on the needs of the whole population rather than singling out individuals for attention.

In this approach, health visitors do not go in with a fixed agenda or a closed choice of predetermined needs to be ratified by clients. They 


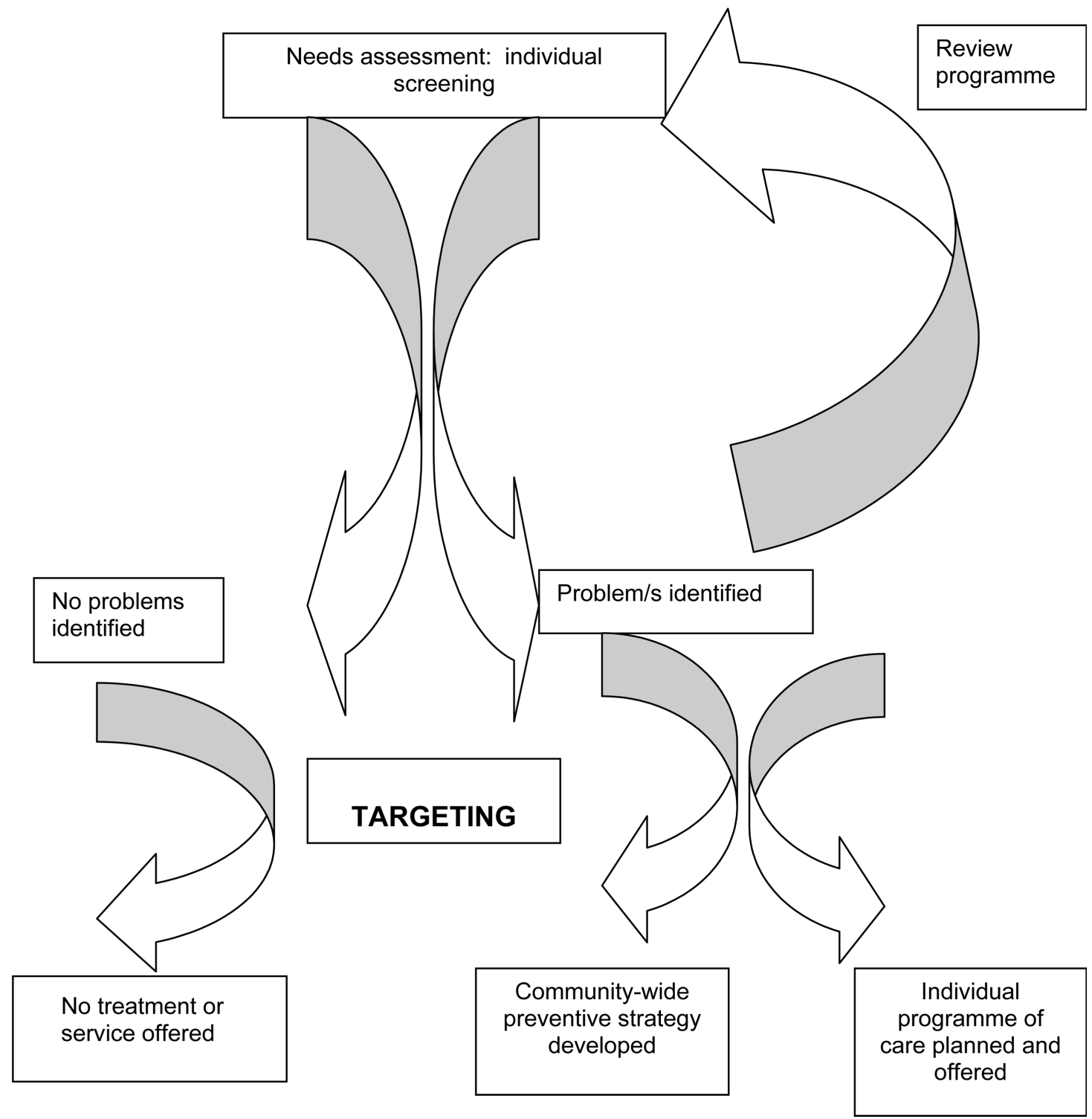

Figure 2 Needs assessment for purposes of targeting

aim, instead, to explore how families can harness their own health creating potential and capacity. Sometimes a trigger tool may be used, such as the validated Familywise cartoon based programme (Glover, 2001), or various open instruments based on a list of words, sentences for completion or an aide-memoire which may be used or left to one side if either health visitor or client feel its use is inappropriate at any particular time (Houston and Cowley, 2002). An initially undirected and open conversational style is used to 'search for health needs', which is a foundation principle of health visiting (CETHV, 1977; Chalmers 1993). Bearing in mind that health visiting is a proactive, unsolicited service, its practitioners need to be prepared to accept and follow shifts in the 
Table 1 Empowerment Approach to Needs Assessment

\begin{tabular}{|c|c|c|}
\hline Relevant health visiting research & Health visiting practice & Intent for client \\
\hline $\begin{array}{l}\text { - Enabling relationships } \\
\text { (Chalmers and Luker, 1991; de } \\
\text { la Cuesta, 1994; Pearson 1991) } \\
\text { - Gaining access/entry work } \\
\text { (Luker and Chalmers, 1990) } \\
\text { - Health promotion work } \\
\text { (Chalmers, 1992) } \\
\text { - Client-centredness; 'fringe } \\
\text { work' (de la Cuesta, 1993) } \\
\text { - Development: changing } \\
\text { expectations (Pearson, 1991) } \\
\text { - Shifting focus in conversation } \\
\text { (Cowley, 1991) } \\
\text { - Unpredicted needs/therapeutic } \\
\text { prevention (Cowley, 1995a) } \\
\text { - Actively promoting resources } \\
\text { for health (Cowley 1995b) }\end{array}$ & $\begin{array}{l}\text { - Health visitor as facilitator and } \\
\text { resource } \\
\text { - Assessment is integral to } \\
\text { practice } \\
\text { - Flexible view of what } \\
\text { constitutes 'need' } \\
\text { - Encourages client-centred } \\
\text { approach to practice } \\
\text { - Allows professional judgement } \\
\text { - Fosters acceptance of the client } \\
\text { view } \\
\text { - Proactive search for health } \\
\text { needs }\end{array}$ & $\begin{array}{l}\text { - Client in the lead } \\
\text { - Promotes 'participatory } \\
\text { competence' } \\
\text { - Non-prescriptive: permitted } \\
\text { needs not predetermined } \\
\text { - Validation of clients } \\
\text { perspective/opinion } \\
\text { - Inclusive of contextual and } \\
\text { sociocultural issues } \\
\text { - Nonstigmatizing } \\
\text { - Assessment as an opportunity } \\
\text { to discuss health, not a } \\
\text { condition for receiving service }\end{array}$ \\
\hline
\end{tabular}

Source: Houston and Cowley, 2002

direction of conversation, responding to cues which may be quite minimal, and either verbal or nonverbal. This shifting focus follows and stimulates awareness of any health needs mentioned in the conversation. The shifting directions are purposeful, being used to maintain open agreement between health visitor and client about the purpose of the contact, enabling topics relevant to the client to be central (Cowley, 1991).

Client-centredness requires the 'fringe work' that lies outside normal organizational agendas, such as arranging appointments at times to suit the client rather than the clinic (de la Cuesta, 1993). Like Cowley, de la Cuesta draws attention to the importance of maintaining mobile role boundaries in order to maintain relevance of the service for clients. Luker and Chalmers (1990) elaborate further, detailing the embedded processes and time needed to accomplish what they call 'entry work'. In addition, the ability to treat problems as if they are 'normal' rather than 'deviant' is shown as an essential prerequisite to the main body of health visiting activity, the 'health promotion work' (Chalmers, 1992). This contrasts strongly with needs assessment protocols that list 'problem areas' for possible discussion.

Health visitor/client relationships are not an end in themselves, but they are facilitative in that they enable health promotion work to be initiated and accomplished (Chalmers and Luker 1991; de la Cuesta, 1994). Development of these relationships is integrally bound in practice with development of the mother as a person, of the mother as a mother and development of the child (Pearson, 1991). These may all be expected to vary considerably during the first year of an infant's life, so expectations the client has of the service and the family's 'health needs' will also change. An assessment undertaken at one point in time, therefore, may well yield quite different results if undertaken with the same family at another time. Health visitors might regularly expect to meet unforeseen and unpredicted needs when undertaking supposedly 'routine' visits in the course of their work (Cowley, 1995a). A key point of the service is that it is generalist in nature, so is able to respond quickly and accurately to a wide range of health promotion needs. If acceptable, this response, in turn, helps clients to both understand the purpose of the health visiting service and to feel able to reveal and discuss otherwise hidden, possibly more relevant and deep-seated, health needs (Collinson and Cowley, 1998a; 1998b).

Thus, client-centredness, needs assessments and access to services are all intertwined and interdependent rather than following a linear process (Appleton and Cowley, 2003; Cowley et al., 2000). The process of 'assessment' is integrated 
within a continuous process involving the key health visiting principles of searching for health needs whilst stimulating an awareness of them and, simultaneously, facilitating health-enhancing activities (CETHV 1977; NMC 2002a). The whole approach occurs as a matrix rather than a cyclical activity as in Figure 3. It is directed at creating health promotion opportunities and encouraging clients to participate in generating their own health resources. The role of the health visitor, in this approach, is intentionally one of partner, facilitator and resource, enabling clients to lead the assessment process and thus increase the chances of them being self-empowered in relation to their own health (Bidmead et al., 2002).

Of course, there is no guarantee that this will always happen, particularly given research that shows that health visitors may, despite expressing enthusiasm for participation, practice in a way that is disempowering (Kendall, 1993), patronizing (de la Cuesta, 1993) or controlling (Abbott and Sapsford, 1990; Mitcheson and Cowley, 2003). However, research has begun to clarify the necessary processes and skills required for the professional judgements involved in identifying vulnerable families and those requiring extra health visiting support (Appleton, 1999; Appleton and Cowley, 2003; Williams, 1997). Individual variation, flexibility and responsiveness are significant in this, the third approach to needs assessment to be detailed in this paper. It is based in a philosophy of empowerment and health pro- motion and grounded in the raft of qualitative studies, cited above and summarized in Table 1, that have been completed in recent years. These studies have unravelled the processes through which health visitors set out to achieve the profession's fundamental and enduring principles of the search for health needs, the stimulation of an awareness of health needs and the facilitation of health enhancing activities (CETHV 1977; NMC 2002a). Further research is urgently needed, now, to assess the extent to which this espoused approach is successful.

The health promotion approach to needs assessment contrasts with, but is complementary to, the linear and predetermined approaches to needs assessment used for prioritizing and targeting specific health needs. As with the other two approaches, it has drawbacks. It tends to focus on individuals and families rather than the context in which they live, so (as with the targeting approach) a specific effort is needed to extend health visiting activities into the local community if the underlying causes of ill-health are to be tackled. Used alone, it does not offer a system by which managers or health service commissioners can measure the activities engaged in by health visitors, nor provide a mechanism for weighting case-loads or assessing the work-load carried by health visitors in a particular area.

Furthermore, this approach relies heavily on the professional skills of the health visitor in engaging the family in assessing their own needs

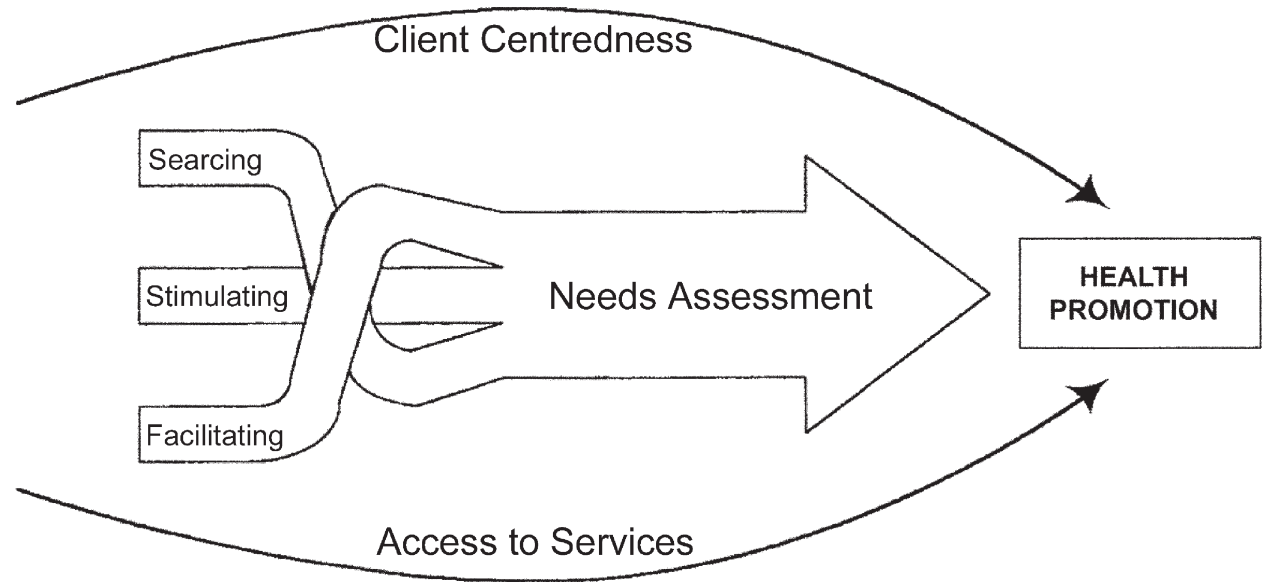

Figure 3 Needs assessment for purposes of health promotion

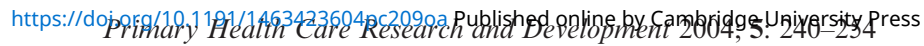


Table 2 Approaches to Needs Assessment in Health Visiting

\begin{tabular}{|c|c|c|}
\hline Primary Purpose & Type & Features \\
\hline Prioritizing & $\begin{array}{l}\text { Public health } \\
\text { approach }\end{array}$ & $\begin{array}{l}\text { - Analagous to epidemiological assessment of needs: depri- } \\
\text { vation scores and population 'risk factors' dominant } \\
\text { - Linked to weighting of caseloads and staffing levels } \\
\text { - Assessment is a single event; separate from practice } \\
\text { - Designed to inform distribution of resources, e.g. to the } \\
\text { - most needy or deprived areas, most vulnerable groups } \\
\text { - Political agenda is high }\end{array}$ \\
\hline Targeting & $\begin{array}{l}\text { Screening } \\
\text { approach }\end{array}$ & $\begin{array}{l}\text { - Intended to ensure that appropriate clinical care reaches } \\
\text { individuals with specific identifiable needs } \\
\text { - Health visitor assessment is seen as analogous to a medical } \\
\text { diagnosis. } \\
\text { - Assessment leads to the 'programme of care' which, ide- } \\
\text { - Ully, should provide demonstrably effective treatments } \\
\text { - Used for service monitoring, tracking achievement of } \\
\text { - Organizational agenda is high }\end{array}$ \\
\hline Health Promotion & $\begin{array}{l}\text { Empowerment } \\
\text { approach }\end{array}$ & $\begin{array}{l}\text { - Emphasis on participation and partnership; aim to extend } \\
\text { this to the wider community. } \\
\text { - Health visitor as facilitator and resource; assessment is a } \\
\text { continuous process bound up with practice } \\
\text { - Clients/families engaged in promoting their own health. } \\
\text { - Assessment process seen as an opportunity to develop } \\
\text { 'participatory competence' in individuals } \\
\text { - Community/client agenda is high }\end{array}$ \\
\hline
\end{tabular}

and, concurrently, identifying ways forward. Having observed the centrality of needs assessment in community practice, Bergen et al. (1996) suggest that educationalists need to pay attention

to developing in practitioners a capacity to exercise professional judgement and a breadth of understanding in their entire role. There is a need for (...) a practitioner who is able to exercise autonomy and professional judgement across the diversity of situations and levels which she is likely to encounter in practice (p. 218).

\section{Conclusion}

This paper has unravelled the conceptual basis of three alternative approaches to needs assessment used in health visiting, of which the key features are summarized in Table 2.

The prioritizing approach offers robust and rigorous information to public health that can help balance, judge and either support or counter the worth of political expectations within any given context. This approach has assumed an even greater importance for health visitors in the UK, since the government began promoting their idea of the 'family-centred public health role' (DH, 1999b; 2001b). The targeting approach supports and promotes the use of clinically effective treatments and can provide health service managers with the kind of orderly prediction, measurement and systems control that is needed to enhance organizational efficiency. This is essential, given the ever-present, but recently emphasized thrust towards efficiency and effectiveness in the modernized NHS (DH 2000). The health promotion approach can elicit hidden as well as overt needs, enhance access to services and work towards clients' empowerment and participation in generating their own resources for health. Again, this is not new, but its importance is emphasized by the government's inequalities agenda (DH 1999b; 2001a; 2003; Independent Inquiry into Inequalities in Health 1998) and the significance of user involvement in recent NHS policy (DH, 2000; 2002b).

Thus, there are important benefits associated with each of the three approaches to needs assess- 
ment. However, each approach has its own specific requirements, and their different uses and conceptual bases give rise to a number of inherent contradictions between them. Sensitivity and flexibility are needed for engaging with individual families, but accurate measurement is needed for systems control. Methodological rigour is required for epidemiological and organizational purposes, but this does not excuse practitioners from the need to maintain high ethical standards of confidentiality and consent. Invalid instruments are never justified. An open agenda and professional judgements do not require scientific validation, but they do need considerable skill to use and to explicate for organizational purposes. Finally, none of the approaches can alter the basic complexity and contested nature of the concept of 'health need', or answer the moral questions about which of many competing needs should be met by health services.

Reflecting on the study that motivated this paper (Cowley and Houston, 2003), it seems that the trust and health commissioners were striving to encompass all three functions outlined in this paper into a single assessment tool. Anecdotally, this appears common, with some trusts even requiring health visitors to administer the tool at a single contact with clients. Given the conflicting nature and different requirements of needs assessment for prioritizing, targeting and health promotion, such an ambitious approach seems doomed to failure. Instead, an integrating system is required, that allows data needed for different purposes to be drawn at different levels, times and through different instruments and methods. In that way, the competing and contradictory, but all important, requirements of public health, of organizational efficiency and user empowerment will best be met.

\section{Acknowledgements}

The study which led to this paper was funded by special research funds from the Florence Nightingale School of Nursing and Midwifery, King's College London. As always, the opinions expressed are the authors' own, but thanks are due to the funders and to the managers, health visitors and clients who helped us to understand the processes of needs assessment more clearly.

\section{References}

Abbott, P. and Sapsford, R. 1990: Health Visiting: Policing the family? In Abbott, P. and Wallace, C. editors, The sociology of the caring professions Basingstoke: Falmer Press, 120-52.

Appleton, J. 1997: Establishing the validity and reliability of clinical practice guidelines used to identify families requiring increased health visitor support. Public Health 111, 107-13.

1999: Assessing vulnerability in families. In McIntosh, J., editor, Research issues in community nursing. Basingstoke: Macmillan, 126-64.

Appleton, J. and Cowley, S. 2003: Valuing professional judgement in health visiting practice. Community Practitioner 76, 215-20.

Bergen, A., Cowley, S., Young, K. and Kavanagh, A. 1996: An investigation into the changing educational needs. of community nurses with regard to needs assessment and quality of care in the context of the NHS and Community Care Act, 1990. Research Report commissioned by English National Board for Nursing, Midwifery and Health Visiting. London: Department of Nursing Studies, King's College.

Benzeval, M., Judge, K. and Whitehead, M. 1995: Tackling inequalities in health: an agenda for action. London: King's Fund.

Bidmead, C., Day, C. and Davis, H. 2002: Partnership working: what does it really mean? Community Practitioner 75, 256-59.

Billings, J. and Cowley, S. 1995: Approaches to community needs assessment: a literature review. Journal of Advanced Nursing 22, 721-30.

Chalmers, K. and Luker, K. 1991: The development of the health visitor-client relationship. Scandinavian Journal of Caring Sciences 5, $33-41$.

Chalmers, K. 1992: Giving and receiving: an empirically derived theory on health visiting practice. Journal of Advanced Nursing 17, 1317-25.

1993: Searching for health needs: the work of health visiting. Journal of Advanced Nursing 18, $900-11$.

Chief secretary to the Treasury. 2003: Every child matters. London: The Stationery Office (Cmd 5860).

Cochrane, M. 1986: The parental empowerment process: building on family strengths. In Harris, J. editor, Child psychology and action. London: Croom Helm, 12-33.

Collinson, S. and Cowley, S. 1998a: Exploring need: taking the marketing perspective. Community Practitioner 71, 244-47. 1998b: An exploratory study of demand for the health visiting service, within a marketing framework. Journal of Advanced Nursing 28, 499-507. 
Council for the Education and Training of Health Visitors (CETHV). 1977: An investigation into the principles of health visiting. London: CETHV.

Cowley, S. 1991: A symbolic awareness context identified through a grounded theory of health visiting. Journal of Advanced Nursing 16, 648-56.

1995a: In health visiting, the routine visit is one that has passed. Journal of Advanced Nursing 22, 276-84.

1995b: Health-as-process: a health visiting perspective. Journal of Advanced Nursing 22, 433-41.

Cowley, S., Bergen, A., Young, K. and Kavanagh, A. 2000: A taxonomy of needs assessment, elicited from a multiple case study of community nursing education and practice. Journal of Advanced Nursing 31, 126-34.

Cowley, S. and Houston, A. 1999: Health visiting and school nursing: the Croydon story. London: Florence Nightingale School of Nursing and Midwifery King's College, (Research report to Croydon Community Health Council).

2003: A structured health needs assessment tool: acceptability and effectiveness for health visiting. Journal of Advanced Nursing 43, 82-92.

Cox, J., Holden, J. and Sagovsky, R. 1987: Detection of postnatal depression. Development of the 10-item Edinburgh Postnatal Depression Scale British Journal of Psychiatry 150, 782-86.

Craig, P. and Smith, L. 1998: Health visiting and public health: back to our roots or a new branch. Health and Social Care in the Community 6, 172-80.

Crompton, K., Davies, M. and Humphries, A. 1998: Child protection: developing an early intervention strategy. Community Practitioner 71, 56-58.

de la Cuesta, C. 1993: Fringe work: peripheral work in health visiting. Sociology of Health and Illness 15, 667-82.

1994: Relationships in health visiting: enabling and mediating. International Journal of Nursing Studies 31, 451-59.

Department of Health (DH). 1999a: Saving lives: our healthier nation. London: The Stationary office (Cmd 4386).

- 1999b: Making a difference: strengthening the nursing, midwifery and health visiting contribution to health and healthcare. London: DH.

2000: The NHS plan: a plan for investment, a plan for reform. London: The Stationary office (Cm 4818-I).

2001a: Tackling health inequalities: consultation on a plan for delivery. London: DH.

2001b: Health visitor practice development resource pack. London: DH.

2002a: Tackling health inequalities: a programme for action. London: DH.

2002b: Liberating the talents: helping primary care trusts and nurses to deliver the NHS plan. London: DH.

2003: Tackling health inequalities: results of the consultation exercise. London: DH.

Department for Education and Employment (DfEE). 1999: Making a difference for children and families: Surestart. London: DfEE.
Dingwall, R. 1977: Collectivism, regionalism and feminism: health visiting and British social policy 1850-1975. Journal of Social Policy 6, 291-315.

Elkan, R., Kendrick, D., Hewitt, M., Robinson, J., Tolley, K., Blair, M., Dewey, M., Williams, D. and Brummell K. 2000: The effectiveness of domiciliary health visiting: a systematic review of international studies and a selective review of the British literature. Health Technology Assessment 4, 13.

2001: Universal vs. selective: the case of British health visiting. Journal of Advanced Nursing 33, 113-19.

Feinstein, L. 1998: Pre-school educational inequality? British children in the 1970 cohort Discussion paper 404. London: London Centre for Economic Performance.

Fonagy, P. 1996: Patterns of attachment, interpersonal relationships and health. In Blane, D., Brunner, E. and Wilkinson, R. Health and social organization: towards a policy for the 21st century. London: Routledge, 125-51.

Glover, A. 2001: Cartoon capers: an update on the Familywise programme. Community Practitioner 74, 60-62.

Gomby, D.S., Culross, P.L. and Behrman, R.E. 1999: Home visiting: recent program evaluations - analysis and recommendations. Future of Children 9, 4-26.

Graham, H. 1999: Inequalities in health: patterns, pathways and policy. Community Practitioner 72, 13-14.

Greenhalgh, T. 1997: How to read a paper: the basics of evidence based medicine. Nottingham: BMJ Publishing Group.

Hanafin, S., Houston, A. and Cowley, S. 2002: Vertical equity in service provision: a model for the Irish public health nursing service. Journal of Advanced Nursing 39, 68-76.

Harris, F. 2002: The first implementation of the Sure Start Language Measure. London: Department of Language and Communication Science, City University.

Hawkins, J. (ed) 1990: Oxford reference dictionary. London: Guild Publishing.

Her Majesty's Treasury, Department of Health. 2002: Tackling health inequalities: summary of the 2002 cross-cutting review. London: Department of Health.

Holden, J., Sagovsky, R. and Cox, J. 1989: Counselling in a general practice setting: controlled study of health visitor intervention in treatment of postnatal depression. British Medical Journal 298, 223-26.

Home Office. 1998: Supporting families: a consultation document. London: The Stationary Office.

Horrocks, S., Pollock, J., Harvey, I., Emond, A. and Shepherd, M. 1998: Health visitor understanding and rating of 28 health and social factors used as part of a health visitor caseload weighting system. Health and Social Care in the Community 6, 343-52.

Houston, A. and Cowley, S. 2002: An empowerment approach to needs assessment in health visiting practice. Journal of Clinical Nursing 11, 640-50.

Houston, A. 2003: Sure Start: a complex community initiative. Community Practitioner 76, 257-60.

Independent Inquiry into Inequalities in Health (chair Acheson, D.) 1998: Independent inquiry into inequalities in health. London: The Stationary Office. 
Kieffer, C. 1984: Citizen empowerment: a developmental perspective. Prevention in Human Services 3, 9-36.

Kendall, S. 1993: Do health visitors promote client participation? An analysis of the health visitor-client interaction. Journal of Clinical Nursing 2, 103-109.

— (ed.) 1998: Health and empowerment London: Arnold.

Lightfoot, J. 1995: Identifying needs and setting priorities: issues of theory, policy and practice. Health and Social Care in the Community 3, 105-14.

Luker, K. and Chalmers, K. 1990: Gaining access to clients: the case of health visiting. Journal of Advanced Nursing 15, $74-82$.

Machen, I. 1996: The relevance of health visiting policy to contemporary mothers. Journal of Advanced Nursing 24, $350-56$.

Mitcheson, J. and Cowley, S. 2003: Empowerment or control? An analysis of the extent to which client participation is enabled during health visitor/client interactions using a structured health needs assessment tool. International Journal of Nursing Studies 40, 413-26.

Naughton, A. and Heath, A. 2001: Developing an early intervention programme to prevent child maltreatment. Child Abuse Review 10, 85-96.

NHS Executive (NHSE) 1996: Child health in the community: a guide to good practice. London: Department of Health.

Normandale, S. 2001: A study of mothers perceptions of the health visiting role. Community Practitioner 74, 146-50.

Nursing and Midwifery Council (NMC). 2002a: Requirements for programmes leading to registration as a health visitor. London: Nursing and Midwifery Council. 2002b: Code of professional conduct for the nurse, midwife and health visitor. London: NMC.
Pearson, P. 1991: Clients perceptions: the use of case studies in developing theory. Journal of Advanced Nursing 16, $521-28$.

Robinson, J. 2000: Effective health care and policy action: the example of health visiting. Journal of Advanced Nursing 32, 1315-17.

Roberts, H. 2000: What is Sure Start? Archives of Disease in Childhood 82, 435-37.

Rowe, J., Wing, R. and Peters, L. 1995: Working with vulnerable families: the impact on health visitor workloads. Health Visitor 68, 232-35.

Shephard, M. 1992: Comparing need with resource allocation. Health Visitor 65, 303-306.

1996: Poverty, health and health visitors. Health Visitor $69,141-43$.

Sure Start Unit. 2001: Sure Start language measure. Information pack October 2001. London: The Sure Start Unit.

Wadsworth, M. 1996: Family and education as determinants of health. In Blane, D., Brunner, E. and Wilkinson, R. editors, Health and social organization: towards a policy for the 21st century London: Routledge, 152-70.

1999: Early life. In Marmot, M. and Wilkinson, R. editors. Social determinants of health. Oxford: Oxford University Press, 44-63.

Wilkinson, R. 1996: Unhealthy societies: the afflictions of inequality. London: Routledge.

Williams, D. 1997: Vulnerable families: a study of health visitors' prioritization of their work. Journal of Nursing Management 5, 19-24.

Young, K.R. and Haynes, R.M. 1993: Assessing population needs in primary health care: the problem of GP attachment. Journal of Interprofessional Care 7, 15-27. 